\title{
Avaliação do efeito combinado da reação álcali-agregado (RAA) e ataque interno por sulfatos (ISA) sobre as resistências mecânicas e microestrutura de argamassas em cura imersa em solução de hidróxido de sódio
}

\author{
Pereira, Elias ${ }^{1}$; Pereira, Eduardo ${ }^{2}$; Pianaro, A. Sidnei ${ }^{3}$; Portella, F. Kleber ${ }^{4}$; \\ Bragança, O. G. P. Mariana ${ }^{5}$; Oliveira, C. Isabela ${ }^{6}$. \\ ${ }^{1}$ Professor, Universidade Estadual de Ponta Grossa e Institutos LACTEC; \\ elias_pereira@outlook.com \\ ${ }^{2}$ Professor, Universidade Estadual de Ponta Grossa; eduardopereira@uepg.br \\ ${ }^{3}$ Professor, Universidade Estadual de Ponta Grossa; sap@uepg.br \\ ${ }^{4}$ Pesquisador, Institutos Lactec, portella@lactec.org.br \\ ${ }^{5}$ Pesquisadora, Institutos Lactec, mariana.portella@lactec.org.br \\ ${ }^{6}$ Mestre, Companhia Paranaense de Energia; isabela.oliveira@copel.com
}

Resumo: Os produtos de matriz cimentícia podem ser acometidos por reações químicas deletérias inerentes aos agregados de sua constituição, destacando-se as reações álcali-agregado (RAA) e ataque interno por sulfatos (ISA). Este trabalho teve por objetivo a análise isolada e combinada das RAA e ISA sobre as propriedades mecânicas de argamassas de cimento Portland, em diferentes idades, em cura totalmente imersa em solução de hidróxido de sódio $(40 \mathrm{~g}$ de $\mathrm{NaOH}$ P.A para $1 \mathrm{~L}$ de água), assim como a investigação de suas mudanças microestruturais. As resistências à compressão e à tração por compressão diametral apresentaram variações, podendo atribuir os ganhos de resistência iniciais à formação de sais de sulfatos que promovem o refinamento e a colmatação de poros, e géis de álcali-sílica, que agregam resistência na zona de transição da interface, em um primeiro momento. Este trabalho foi desenvolvido no âmbito do Programa de P\&D ANEEL, projeto $6491-0301 / 2013$

Palavras-chave: Ataque por sulfatos de origem interna, Reação álcali-agregado, Durabilidade, Resistência à tração, Resistência à compressão.

Abstract: Cement matrix products can be affected by deleterious chemical reactions inherent to the aggregates of their constitution, especially the alkali-aggregate (RAA) and internal sulfate (ISA) reactions. The objective of this work was the isolated and combined analysis of the RAA and ISA on the mechanical properties of Portland cement mortars, at different ages, in a totally immersed cure in sodium hydroxide solution $(40 \mathrm{~g}$ of $\mathrm{NaOH}$ to $1 \mathrm{~L}$ of water) such as the investigation of its microstructural changes. The compressive and diametrical compression tensile strengths presented variations, being able to attribute the initial resistance gains to the formation of sulfate salts that promote the refinement and the clogging of pores, and alkali-silica gels, which add resistance in the transition zone of the interface, at a first moment. This paper was developed under the Program of P\&D ANEEL, project 6491-0301/2013.

Keywords: Sulphate attack, Alkali-aggregate reaction, Durability, Tensile strength, Compressive strength. 
PEREIRA, E. et al., AVALIAÇÃO DO EFEITO COMBINADO DA REAÇÃO ÁLCALI-AGREGADO (RAA) E ATAQUE INTERNO POR

SULFATOS (ISA) SOBRE AS RESISTÊNCIAS MECÂNICAS E MICROESTRUTURA DE ARGAMASSSAS EM CURA IMERSA EM SOLUÇÃO DE HIDRÓXIDO DE SÓDIO. $3^{\circ}$ Simpósio Paranaense de Patologia das Construções (30 SPPC), artigo 3SPPC1008, pp. 84 - 95, 2018. DOI: $10.4322 / 2526-7248.008$

\section{Introdução}

O ataque por sulfatos de origem interna devido à presença de sulfetos minerais no concreto ocorre pela reação química entre estes sulfetos com o oxigênio, a água e os compostos de hidratação do cimento. Estas reações podem originar compostos expansivos dentro da matriz cimentícia, como íons férricos, etringita e gipsita, que acarretam em tensões sobressalentes dentro da estrutura, fissuras, deslocamentos e redução da resistência mecânica $[1,2,3]$.

A reação álcali-agregado (RAA) é um mecanismo de degradação entre constituintes mineralógicos dos agregados com hidróxidos alcalinos liberados na hidratação do cimento que estejam dissolvidos na solução dos poros do concreto. O produto da reação é a formação de uma substância viscosa na forma de gel com características expansivas. Por ser higroscópico, atrai moléculas de água, as quais migram através da pasta de cimento podendo gerar elevadas expansões no interior do material. As principais características apresentadas são a presença de mancha e exsudação do gel na superfície do concreto, deslocamento de peças estruturais e fissuras desordenadas na superfície do concreto na forma de mapa [4]. Esta reação tem ocasionado a degradação de diversas estruturas, tais como barragens, fundações de pontes, usinas de geração de energia e estruturas marinhas [5, 6]. Foradada [7], relata no meio técnico mais de 140 casos de barragens afetadas pela RAA.

Tanto a RAA como o ISA podem ser precursores de outras manifestações patológicas, visto que geram fissuras que se tornam pontos para a entrada de umidade, oxigênio e outros agentes agressivos para o interior das estruturas. Como característica para os mecanismos citados, verifica-se que o agregado é o ponto convergente para ambos, podendo em alguns casos o mesmo mineral conter além de sulfeto também apresentar reatividade álcali-agregado, conforme relatado por Pereira [3]. Sob esta perspectiva, o estudo conjugado das reações álcali-agregado e de ataque interno por sulfatos são um desafio para o estudo de ciência dos materiais e de engenharia civil uma vez que ambas as reações ainda apresentam lacunas de conhecimento acerca dos mecanismos de degradação e por praticamente inexistência de métodos de reparo que atuem de forma definitiva sobre o material.

Baseado no exposto, o objetivo deste trabalho foi observar as alterações mecânicas das argamassas com ocorrencia do efeito isolado e combinado da RAA e ISA pela presença de fases deletérias nos agregados, em cura totalmente imersa em solução de hidróxido de sódio, sendo a microestrutura analisada por microscopia eletrônica de varredura e difração de raios $X$.

\section{Materiais e Métodos}

Como agregado miúdo, utilizou-se quatro areias distintas, sendo: (i) areia quartzosa natural do rio Tibagi coletada na cidade de Ponta Grossa (chamado de "Referência"); (ii) areia quartzosa com adição de 5\% de pirita (chamado de "Pirita"); (iii) areia de britagem contendo sulfeto de ferro (pirita) e fases reativas aos álcalis do cimento (chamado de "Pedreira") e, por fim, (iv) areia de britagem com potencial reativo aos álcalis do cimento (chamada de "RAA"). 
PEREIRA, E. et al., AVALIAÇÃO DO EFEITO COMBINADO DA REAÇÃO ÁLCALI-AGREGADO (RAA) E ATAQUE INTERNO POR SULFATOS (ISA) SOBRE AS RESISTÊNCIAS MECÂNICAS E MICROESTRUTURA DE ARGAMASSSAS EM CURA IMERSA EM SOLUÇÃO DE HIDRÓXIDO DE SÓDIO. $3^{\circ}$ Simpósio Paranaense de Patologia das Construções (30 SPPC), artigo 3SPPC1008, pp.

Os agregados miúdos foram caracterizados conforme a NBR 7211: (2009) [9], determinação da distribuição granulométrica (NBR NM 248: 2003) [10], massa específica e massa específica aparente (NBR NM 52: 2009) [11], massa unitária (NBR NM 45: 2006) [12] e determinação do material fino que passa através da peneira de $75 \mu \mathrm{m}$ (material pulverulento), por lavagem (NBR NM 46: 2003) [13]. A caracterização química dos agregados foi, ainda, executada por meio do FRX. Os resultados de caracterização estão apresentados nas Tabelas 1 e 2.

Tabela 1: Caracterização física dos agregados

\begin{tabular}{c|c|c|c|c|c}
\hline Propriedades & Referência & Pedreira & RAA & Pirita & $\begin{array}{c}\text { Pirita de } \\
\text { adição }\end{array}$ \\
\hline Massa específica $\left(\mathrm{g} / \mathrm{cm}^{3}\right)$ & 2,63 & 1,73 & 2,61 & 2,63 & 2,43 \\
\hline Massa unitária $\left(\mathrm{kg} / \mathrm{m}^{3}\right)$ & 1,622 & 1,862 & 1,490 & 1,640 & 1,691 \\
\hline \% de material pulverulento & 3,62 & 17,78 & 14,10 & 3,70 & 47,9 \\
\hline Módulo de finura & 2,94 & 3,77 & 3,58 & 2,86 & 3,58 \\
\hline
\end{tabular}

Estes resultados evidenciam principalmente a proporção de maior parcela de finos nos agregados Pedreira e RAA, fato que pode atribuir maior reatividade devido maior área superficial destes.

Tabela 2: Caracterização química dos agregados por fluorescências de raios $\mathrm{X}(\%)$

\begin{tabular}{ccccccccccccc}
\hline Agregado & $\mathbf{S i O}_{2}$ & $\mathbf{A l}_{2} \mathbf{O}_{3}$ & $\mathbf{C a O}$ & $\mathbf{F e}_{2} \mathbf{O}_{3}$ & $\mathbf{K}_{2} \mathbf{O}$ & $\mathbf{T i O}_{2}$ & $\mathbf{M g O}$ & $\mathbf{N a}_{2} \mathbf{O}$ & $\mathbf{M n O}$ & $\mathbf{P}_{2} \mathbf{O}_{5}$ & $\mathbf{S O}_{3}$ & P.F \\
\hline Referência & 88,99 & 3,16 & 2,58 & 2,11 & 1,45 & 1,10 & - & - & - & - & - & - \\
\hline RAA & 70,84 & 15,73 & 1,43 & 1,02 & 3,63 & 0,19 & 0,31 & 5,52 & 0,02 & 0,07 & - & 1,07 \\
\hline Pedreira & 47,10 & 13,00 & 9,10 & 18,30 & 1,50 & - & 2,80 & 2,50 & - & 0,80 & 0,30 & - \\
\hline Pirita & 1,50 & 0,60 & 1,40 & 20,40 & $<0,10$ & $<0,10$ & - & 0,10 & $<0,10$ & - & 35,50 & 40,00 \\
\hline
\end{tabular}

* P.F - Perda ao fogo procedida em mufla.

Estes resultados da Tabela 2 demonstram que o agregado de Referência é composto principalmente por cristais de quartzo, os quais podem apresentar reatividade reduzida aos álcalis totais das argamassas. O agregado RAA é composto principalmente por quartzo com parcelas reativas, mas também apresenta proporções de álcalis em sua constituição, característicos de feldspatos alcalinos, os quais agregam reatividade ao agregado. O agregado Pedreira apresenta frações de sulfetos em sua constituição, demosntrando a possibilidade da ocorrência do ISA, além da proporção predominante de quartzo com parcelas reativas. O agregado Pirita é composto pelo agregado Referência com a substituição de $5 \%$ em massa por pirita, sendo que pode-se observar grande quantidade de sulfetos na pirita de adição, fator preponderante para a ocorrência do ISA.

A pirita utilizada para a adição na areia foi proveniente da região de Figueira e Ortigueira - PR, sendo um resíduo proveniente do processo de beneficiamento de carvão mineral. O aglomerante utilizado foi o cimento Portland CPII-F 32, sendo que os resultados de sua caracterização físico-química foram fornecidos pelo fabricante apresentados na Tabela 3 . Estes resultados indicam que o cimento segue as características exigidas pela NBR 11578 [17] para cimentos compostos, podendo ser replicados estes ensaios com cimentos comerciais desta classe.

Para a moldagem das argamassas foi utilizado um traço único para todas as análises, de 1 (uma) parte de cimento para 3,2 partes de agregado miúdo para que 
PEREIRA, E. et al., AVALIAÇÃO DO EFEITO COMBINADO DA REAÇÃO ÁLCALI-AGREGADO (RAA) E ATAQUE INTERNO POR SULFATOS (ISA) SOBRE AS RESISTÊNCIAS MECÂNICAS E MICROESTRUTURA DE ARGAMASSSAS EM CURA IMERSA EM SOLUÇÃO DE HIDRÓXIDO DE SÓDIO. $3^{\circ}$ Simpósio Paranaense de Patologia das Construções (30 SPPC), artigo 3SPPC1008, pp. 84 - 95, 2018. DOI: $10.4322 / 2526-7248.008$

pudesse se obter uma mistura homogênea para os diferentes agregados. A relação água/cimento foi de 0,60 . As condições de mistura foram procedidas conforme NBR 7215 (ABNT, 1996) [8].

Tabela 3: Caracterização física química do cimento CPII-F-32

\begin{tabular}{|c|c|c|c|c|c|c|c|c|c|c|c|c|}
\hline \multicolumn{13}{|c|}{ Ensaios Químicos } \\
\hline $\begin{array}{c}\text { Perda ao } \\
\text { fogo } \\
\%\end{array}$ & $\begin{array}{c}\mathrm{Al}_{2} \mathrm{O}_{3} \\
\%\end{array}$ & \multicolumn{2}{|l|}{$\begin{array}{c}\mathrm{SiO}_{2} \\
\%\end{array}$} & $\begin{array}{c}\mathrm{Fe}_{2} \mathrm{O}_{3} \\
\%\end{array}$ & \multicolumn{2}{|c|}{$\begin{array}{c}\mathrm{CaO} \\
\%\end{array}$} & $\underset{\%}{\mathrm{MgO}}$ & $\begin{array}{c}\mathrm{SO}_{3} \\
\%\end{array}$ & $\begin{array}{c}\mathrm{CaO} \\
\text { Livre } \\
\%\end{array}$ & $\begin{array}{c}\text { Equiv. } \\
\text { Alcal } \\
\%\end{array}$ & \multicolumn{2}{|c|}{$\begin{array}{c}\text { Resíduo } \\
\text { Insolúvel } \\
\%\end{array}$} \\
\hline 4,89 & 4,22 & 18,62 & & 2,62 & & 00 & 3,93 & 2,74 & 0,62 & 0,70 & & 1,44 \\
\hline \multicolumn{13}{|c|}{ Ensaios Físicos } \\
\hline $\begin{array}{c}\text { Massa } \\
\text { Especif. } \\
\mathrm{g} / \mathrm{cm}^{3}\end{array}$ & $\begin{array}{c}\text { Exp. } \\
\text { Quente } \\
\text { Mm }\end{array}$ & $\begin{array}{l}\text { Início } \\
\text { da } \\
\text { pega } \\
\text { h:min }\end{array}$ & $\begin{array}{c}\text { Fim } \\
\text { de } \\
\text { pega } \\
\text { h:min }\end{array}$ & & & $\begin{array}{l}\text { Blaine } \\
\mathrm{cm}^{2} / \mathrm{g}\end{array}$ & $\begin{array}{c}\text { Retido } \\
\text { na } \\
\# 200 \\
\%\end{array}$ & $\begin{array}{c}\text { Retido } \\
\text { na \# } \\
325 \\
\%\end{array}$ & $\begin{array}{l}1 \mathrm{dia} \\
\mathrm{MPa}\end{array}$ & $\begin{array}{c}3 \\
\text { dias } \\
\text { Mpa }\end{array}$ & $\begin{array}{c}7 \\
\text { dias } \\
\text { MPa }\end{array}$ & $\begin{array}{c}28 \\
\text { dias } \\
\mathrm{MPa}\end{array}$ \\
\hline 3,08 & 0,21 & $04: 17$ & 05:01 & & & 3.248 & 1,95 & 12,63 & 13,0 & 27,2 & 33,6 & 41,0 \\
\hline
\end{tabular}

A cura dos corpos de prova foi feita em 2 etapas seguindo o exposto pela NBR 13583 [14]: i) 2 dias em temperatura ambiente e ii) 12 dias em água saturada com cal, conforme recomendação normativa. Para o restante das análises não foi seguido o referenciado pela NBR 13583 [14], sendo apenas utilizada esta forma inicial de cura para a hidratação do cimento de forma padronizada. As caracterizações das propriedades físicas das argamassas foram avaliadas nas idades de 28, 90, 220 e 360 dias.

Para a caracterização das propriedades físicas das argamassas foram executados os ensaios de compressão axial (NBR 5739: 2007) [15] e tração por compressão diametral (NBR 7222: 2011) [16]. Foram ensaiados 5 corpos de prova por metodologia em cada idade de monitoramento. Para os ensaios de resistência à compressão e tração, utilizou-se uma prensa com capacidade de 10 toneladas força de capacidade, com controle de velocidade de aplicação de carga.

Os ensaios de DRX foram procedidos em difratômetro PANalytical EMPYREAN em pastilhas de pó prensados, com o objetivo de avaliar as fases minerais presentes nas amostras. O preparo das amostras para a coleta dos difratogramas foi realizado pela prensagem manual no próprio porta-amostra. A mensuração foi realizada entre $5^{\circ}$ e $75^{\circ}$ em varredura angular $2 \theta$, com passo de $0,02^{\circ} 2 \theta$ e tempo por passo de $1 \mathrm{~s}$. $\mathrm{Na}$ análise foi utilizado um tubo com ânodo de cobre, $40 \mathrm{kV} / 30 \mathrm{~mA}$ e uma fenda divergente de $1^{\circ}$. As fases químicas minerais foram identificadas por comparação com os padrões do ICDD (International Centre for Diffraction Data).

Para a análise estatística foi utilizado o Teste de Tukey com $5 \%$ de probabilidade de erro. O software utilizado foi o ASSISTAT Versão 7.7 beta (2015) desenvolvido pelo Professor Francisco Silva da Universidade Federal de Campina Grande.

Os ensaios executados foram realizados nos laboratórios LAME/LACTEC, LAMIR/UFPR, C-LABMU/UEPG e Laboratório Interdisciplinar de Materiais Cerâmicos (LIMAC/UEPG) e Laboratórios de Materiais de Construção da Engenharia Civil da UEPG. 
PEREIRA, E. et al., AVALIAÇÃO DO EFEITO COMBINADO DA REAÇÃO ÁLCALI-AGREGADO (RAA) E ATAQUE INTERNO POR SULFATOS (ISA) SOBRE AS RESISTÊNCIAS MECÂNICAS E MICROESTRUTURA DE ARGAMASSSAS EM CURA IMERSA EM SOLUÇÃO DE HIDRÓXIDO DE SÓDIO. $3^{\circ}$ Simpósio Paranaense de Patologia das Construções (30 SPPC), artigo 3SPPC1008, pp.

\section{Resultados e Discussões}

Nas Figuras 1 e 2 estão apresentados, respectivamente, os valores de resistência à compressão e à tração por compressão diametral dos corpos de prova em cura totalmente imersa em solução de hidróxido de sódio em temperatura ambiente. Nas Tabelas 4 e 5, estão apresentados os resultados do tratamento estatístico referente a estes valores.

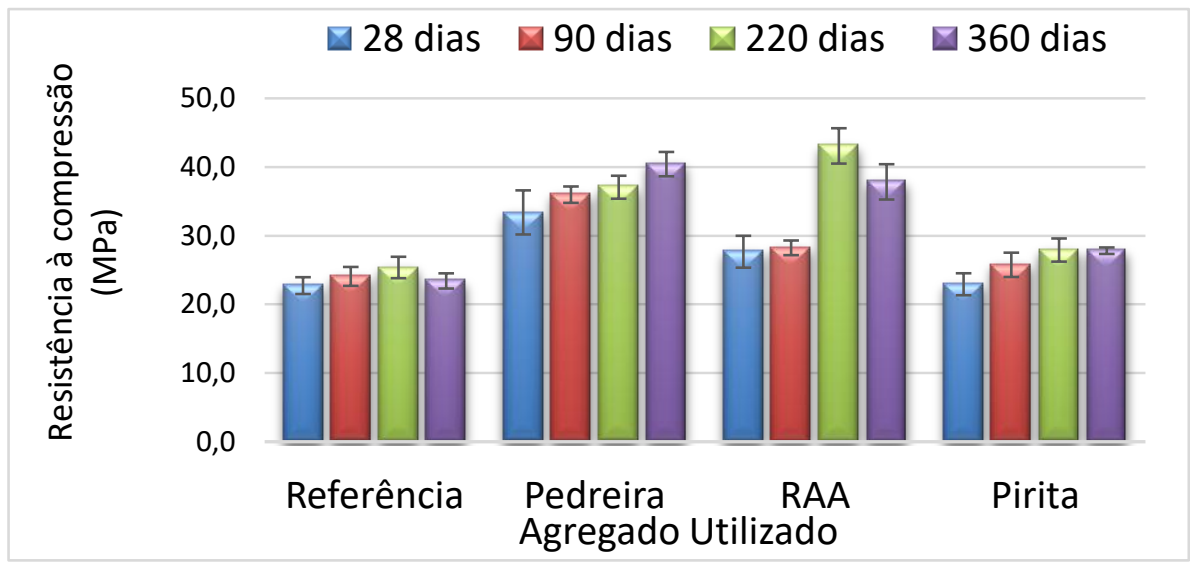

Figura 1: Resistência à compressão de corpos de prova cilíndricos das argamassas nas idades de 28, 90, 220 e 360 dias em cura totalmente imersa em solução de hidróxido de sódio em temperatura ambiente

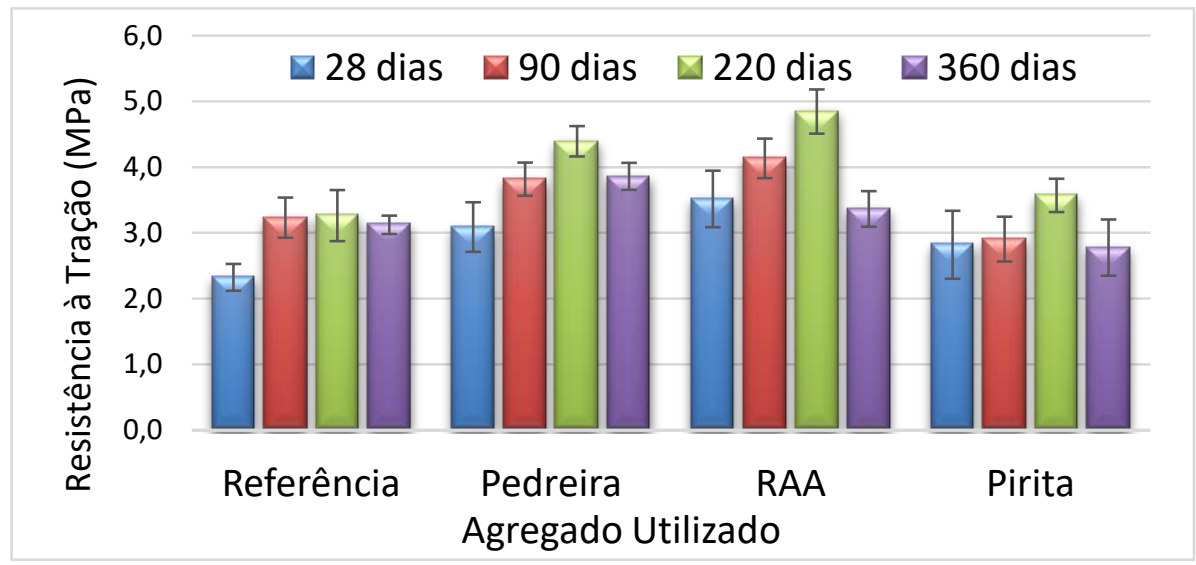

Figura 2: Resistência à tração por compressão diametral de corpos de prova cilíndricos das argamassas nas idades de 28, 90, 220 e 360 dias em cura totalmente imersa em solução de hidróxido de sódio em temperatura ambiente

Tabela 4: Teste de Tukey para a influência das diferentes idades na resistência à compressão dos corpos de prova de concreto

\begin{tabular}{ccccc}
\hline & \multicolumn{3}{c}{ Idade (dias) } \\
\hline Agregados & $\mathbf{2 8}$ & $\mathbf{9 0}$ & $\mathbf{2 2 0}$ & $\mathbf{3 6 0}$ \\
\hline Referência & $\mathrm{a}$ & $\mathrm{A}$ & $\mathrm{a}$ & $\mathrm{a}$ \\
\hline Pedreira & $\mathrm{a}$ & $\mathrm{B}$ & $\mathrm{C}$ & $\mathrm{d}$ \\
\hline RAA & $\mathrm{a}$ & $\mathrm{A}$ & $\mathrm{bc}$ & $\mathrm{C}$ \\
\hline Pirita & $\mathrm{a}$ & $\mathrm{A}$ & $\mathrm{b}$ & $\mathrm{c}$ \\
\hline
\end{tabular}


PEREIRA, E. et al., AVALIAÇÃO DO EFEITO COMBINADO DA REAÇÃO ÁLCALI-AGREGADO (RAA) E ATAQUE INTERNO POR SULFATOS (ISA) SOBRE AS RESISTÊNCIAS MECÂNICAS E MICROESTRUTURA DE ARGAMASSSAS EM CURA IMERSA EM SOLUÇÃO DE HIDRÓXIDO DE SÓDIO. $3^{\circ}$ Simpósio Paranaense de Patologia das Construções (30 SPPC), artigo 3SPPC1008, pp. 84 - 95, 2018. DOI: $10.4322 / 2526-7248.008$

Tabela 5: Teste de Tukey para a influência das diferentes idades na resistência à tração por compressão diametral dos corpos de prova de concreto

\begin{tabular}{ccccc}
\hline \multicolumn{5}{c}{ Idade (dias) } \\
\hline Agregados & $\mathbf{2 8}$ & $\mathbf{9 0}$ & $\mathbf{2 2 0}$ & $\mathbf{3 6 0}$ \\
\hline Referência & $\mathrm{a}$ & $\mathrm{bcd}$ & $\mathrm{Cd}$ & $\mathrm{d}$ \\
\hline Pedreira & $\mathrm{a}$ & $\mathrm{Bd}$ & $\mathrm{Cd}$ & $\mathrm{d}$ \\
\hline RAA & $\mathrm{a}$ & $\mathrm{B}$ & $\mathrm{C}$ & $\mathrm{a}$ \\
\hline Pirita & $\mathrm{a}$ & $\mathrm{A}$ & $\mathrm{B}$ & $\mathrm{a}$ \\
\hline
\end{tabular}

As resistências à compressão dos corpos do agregado Referência (Figura 1) não apresentaram alterações durante as idades de controle, demonstrando que mesmo em solução fortemente alcalina os agregados de referência não apresentam reatividade aos íons de sódio no período analisado. As resistências à tração por compressão diametral apresentaram uma variação entre 28 e 90 dias de $28,1 \%$ em relação aos valores iniciais, permanecendo sem alterações até o período observado.

O agregado de referência mostrou-se inerte aos álcalis tanto do cimento quanto da forma de cura, sendo que não puderam ser observadas alterações na microestrutura das amostras pelo ensaio de microscopia. Na Figura 4 estão apresentados os difratogramas de raio $X$ dos corpos de prova com agregado de Referência em sua composição, onde pode ser observado que não ocorreram alterações durante as idades de controle, sem a identificação de gipsita, referente ao ataque interno por sulfatos.

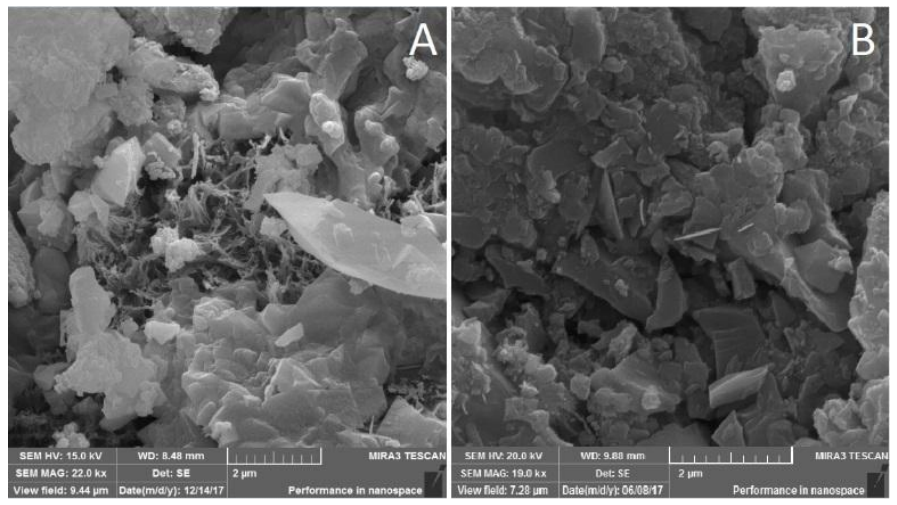

Figura 3: Microscopia das argamassas constituídas com agregado Referência em cura totalmente imersa em solução de hidróxido de sódio: (a) aos 28 dias; (b) aos 360 dias

As resistências à compressão das argamassas com agregado Pedreira (Figura 1) apresentaram aumento gradativo de $17,3 \%$ durante as idades de medida. As resistências à tração por compressão diametral (Figura 2) apresentaram um aumento gradativo de 29,5\% aos 220 dias, com uma diminuição de 11,36\% aos 360 dias. Yurtdas [18] observou mesmo comportamento em seu trabalho, em que a reação álcali agregado culminou no aumento de resistência à compressão de argamassas mantidas em cura úmida a $60^{\circ} \mathrm{C}$, assim como um incremento das resistências à tração com uma posterior queda nas idades finais, demonstrando que a formação de fases expansivas pode ter ocasionado microfissuras causando esta redução de resistência. 


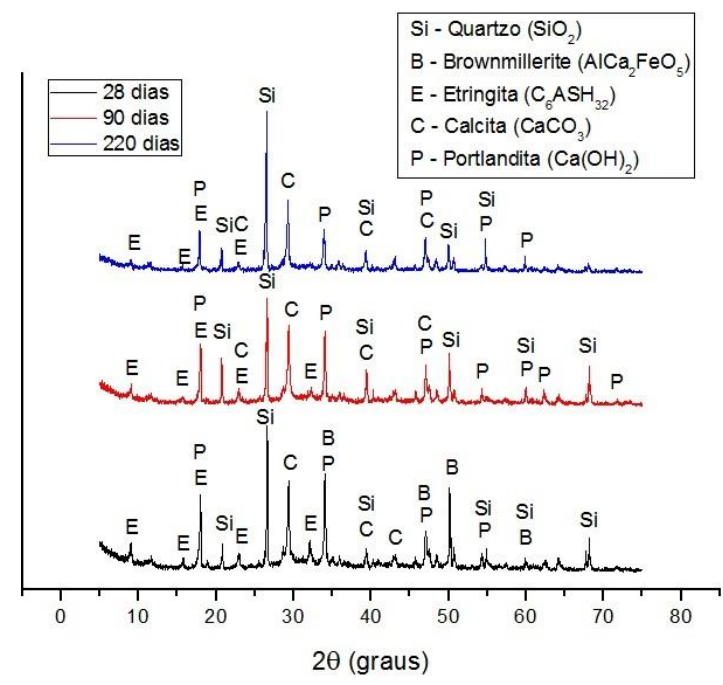

Figura 4: Difratogramas de raio $X$ dos corpos de prova confeccionados com 0 agregado Referência aos 28,90 e 220 dias

Na Figura 5 é possível observar que o agregado Pedreira tem reagido com os álcalis do cimento e da solução alcalina desde o início do processo de cura, sendo visíveis pontos de dissolução e pequenas inclusões nas faces dos agregados. É importante salientar que os sulfetos presentes no agregado Pedreira não influenciaram nas resistências à compressão e tração, fato confirmado pelas análises de microscopia, onde cristais de sulfatos não foram encontrados no decorrer das idades de análise.
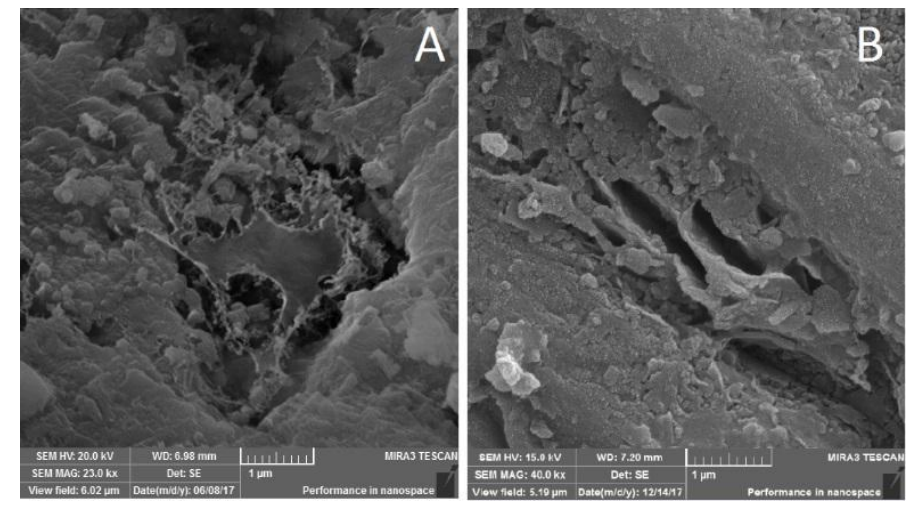

Figura 5: Microscopia das argamassas com agregado Pedreira em cura totalmente imersa em solução de hidróxido de sódio: (a) aos 28 dias e (b) aos 360 dias

Na Figura 6 estão apresentados os difratogramas de raio $X$ referentes aos corpos de prova com agregado Pedreira.

Pode ser notada uma diminuição da ocorrência de portlandita aos 220 dias, fato que pode ter ocorrido pela sua dissolução e utilização nos processos de troca iônica com o gel álcali-sílica recorrente da RAA. Este fato, juntamente com as diminuições de resistência à tração e microscopias de agregados em dissolução, podem ser oriundos do processo de reatividade dos agregados aos álcalis da solução e do cimento e a formação de fases expansivas deletérias. 


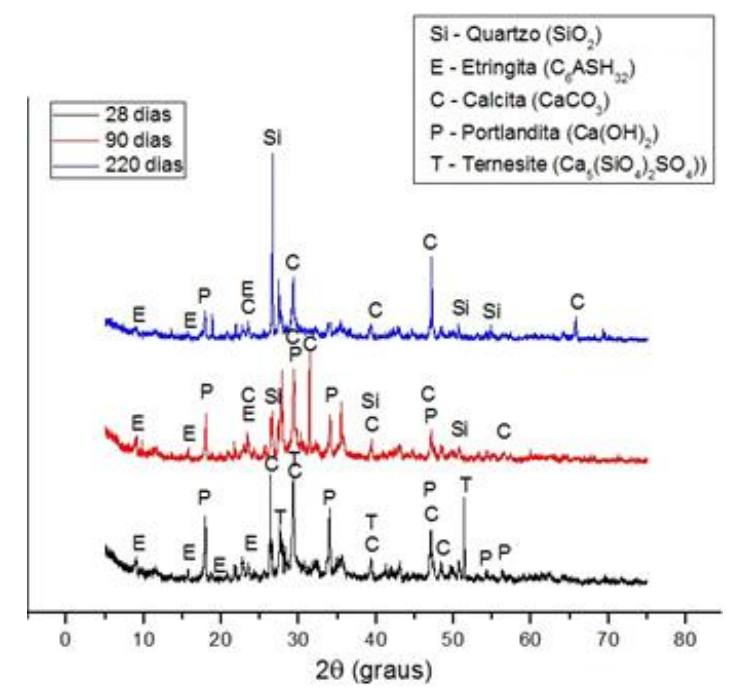

Figura 6: Difratogramas de raio $X$ dos corpos de prova confeccionados com 0 agregado Pedreira aos 28,90 e 220 dias

As resistências à compressão referentes ao agregado RAA (Figura 1) apresentam um aumento de $34,6 \%$ entre as idades de 90 e 220 dias, com uma posterior queda aos 360 dias de 12,3\%. Este comportamento demonstra que ocorreu um período inicial de dormência das reações quanto a resistência à compressão, característico do início da formação dos géis referentes à reação álcali-agregado, com um posterior aumento de resistência à compressão pelo preenchimento dos poros próximos a interface entre agregados e pasta por estes géis. Esta perda final de resistência demonstra que a formação de produtos expansivos pode ter causado microfissuras decorrentes das tensões aplicadas na matriz de poros das argamassas, assim como a formação de uma dupla camada elétrica entre os íons. Yurtdas [18] observou mesmo comportamento de resistência mecânicas para agregados reativos.

As resistências à tração por compressão diametral referentes aos agregados RAA (Figura 2) apresentaram o mesmo padrão observado nas resistências à compressão, com um aumento gradativo até os 220 dias de 27,1\% e posterior queda de $29,2 \%$ aos 360 dias, demonstrando a influência da formação de géis álcali-sílica para os incrementos de resistências em idades inicias com posteriores perda a partir do momento que tensões de tração são empreendidas pelas fases expansivas. As Figura 7 (a) e (b) apresentam partículas de agregado com característica de reação álcali agregado com as fases reativas solubilizando-se na solução alcalina, onde não foi possível observar a presença de gel característico da reação álcali agregado no interior de macroporos, demonstrando que as reações têm ocorrido em poros de escalas nanométricas.

Na Figura 8 estão apresentados os difratogramas de raio $X$ dos corpos de prova com agregado RAA, onde não pode ser observada nenhuma alteração significativa entre as idades de controle.

As resistências à compressão referentes ao agregado Pirita apresentaram um aumento entre as idades de 28 e 90 dias de 10,9\%, com um posterior 
comportamento de estagnação nas demais idades. As resistências à tração por compressão diametral apresentaram um pico aos 220 dias de cerca de $22,2 \%$, sendo que os demais valores permaneceram sem variações. As variações neste caso podem ter ocorrido pela oxidação dos sulfetos contaminantes do agregado e consequente formação de cristais de sulfatos, os quais em um primeiro momento auxiliam nas resistências mecânicas pelo efeito de refinamento e tamponamento de poros e que em um segundo momento geram tensões internas ao material com uma consequente formação de fissuras e diminuição das resistências, assim como observado por Pereira [3]. Na Figura 9 está apresentada a formação de cristais de sulfatos dentro de poros da argamassa aos 220 e 360 dias. Na Figura 9(a) está apresentado um detalhe de um poro com a sua superfície toda preenchida por cristais de sulfatos, inclusive no interior de uma fissura, e na Figura 9(b) está apresentado um poro já colmatado por estes cristais, demonstrando o avanço das reações.
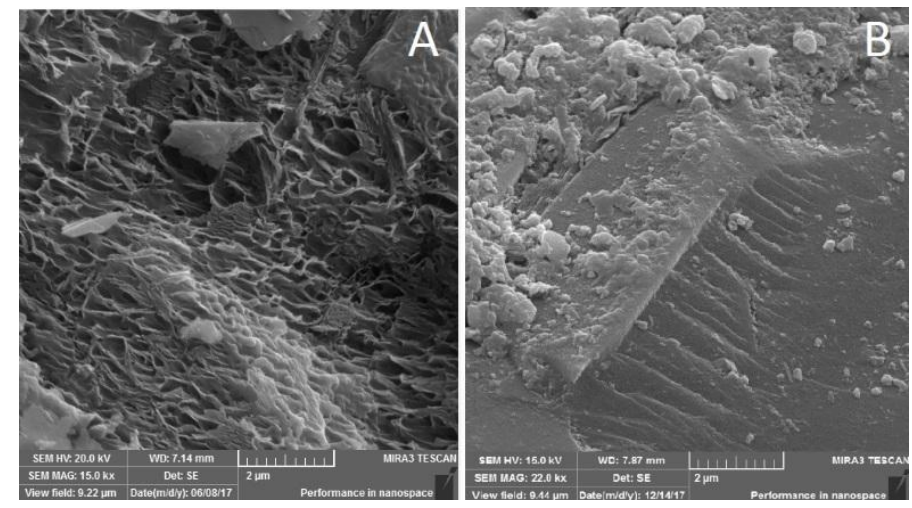

Figura 7: Microscopia das argamassas constituídas com agregado RAA em cura totalmente imersa em solução de hidróxido de sódio: (a) aos 28 dias e (b) aos 360 dias

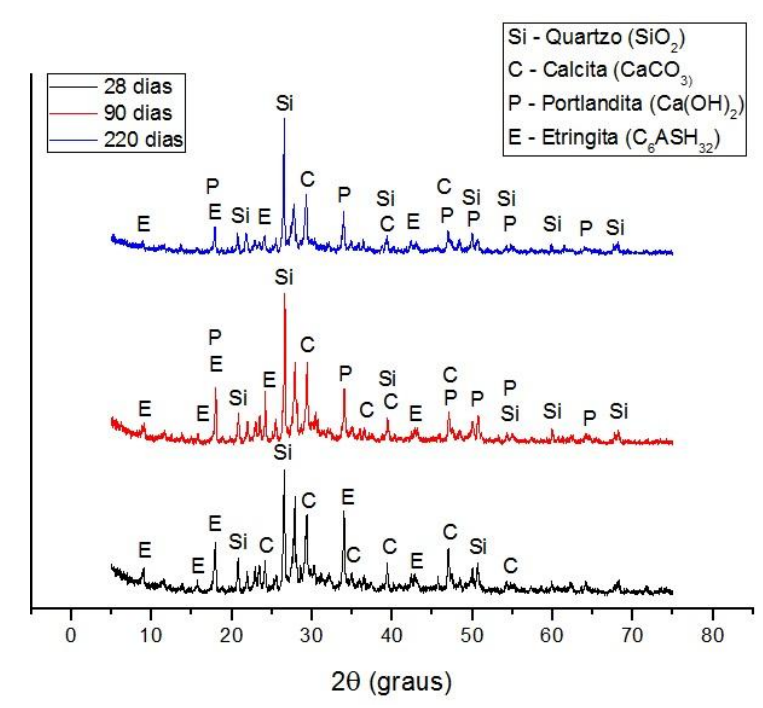

Figura 8: Difratogramas de raio $X$ dos corpos de prova confeccionados com 0 agregado RAA aos 28,90 e 220 dias 

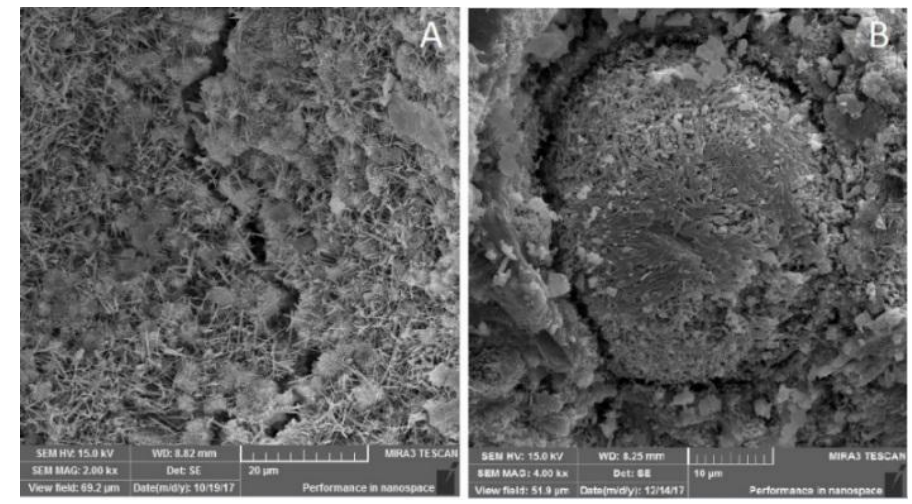

Figura 9: Microscopia das argamassas constituídas com agregado Pirita em cura totalmente imersa em solução de hidróxido de sódio: (a) 220 dias; (b) 360 dias

Nos resultados de difração de raios x (Figura 10) pode ser observada a ocorrência de gipsita aos 220 dias, fato que, juntamente com as resistências mecânicas crescentes até esta idade, imagens de microscopia comprovam a ocorrência do ataque por sulfatos até mesmo em ambiente extremamente alcalino e com proporção restrita de oxigênio devido à cura totalmente imersa em solução de hidróxido de sódio.

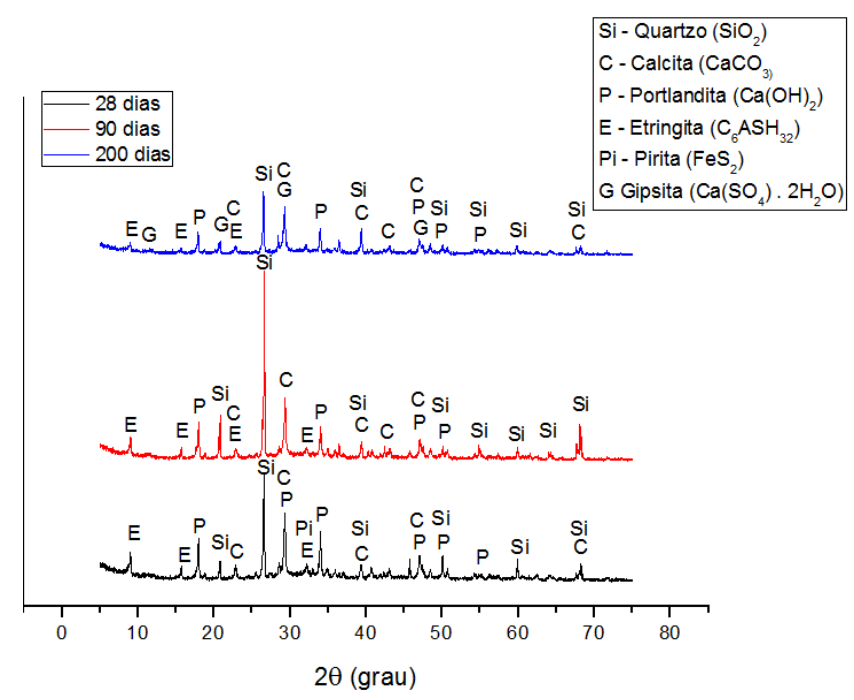

Figura 10: Difratogramas de raio $X$ dos corpos de prova confeccionados com o agregado Pirita aos 28,90 e 220 dias

\section{Conclusões}

Sendo assim, não foi possível observar o efeito combinado da RAA e ISA na forma de cura em solução de hidróxido de sódio, visto que para o agregado Pedreira, o qual apresenta as duas manisfestações patológicas, não foi notada a formação de sais de sulfatos pela variação da proporção de sulfetos minerais em sua constituição assim como a menor proporção de oxigenação na forma de cura totalmente imersa, acarretando na intensificação apenas da reação álcali agregado. Desta forma, a cura em solução de hidróxido não é indicada para a análise do efeito combinado 
PEREIRA, E. et al., AVALIAÇÃO DO EFEITO COMBINADO DA REAÇÃO ÁLCALI-AGREGADO (RAA) E ATAQUE INTERNO POR SULFATOS (ISA) SOBRE AS RESISTÊNCIAS MECÂNICAS E MICROESTRUTURA DE ARGAMASSSAS EM CURA IMERSA EM SOLUÇÃO DE HIDRÓXIDO DE SÓDIO. $3^{\circ}$ Simpósio Paranaense de Patologia das Construções (30 SPPC), artigo 3SPPC1008, pp.

para os agregados estudados, onde a reação álcali-agregado é intensificada pela disponibilidade de álcalis da solução.

Nas argamassas com os agregados Pedreira e RAA, pela ocorrência da reação álcali-agregado foi possível observar aumentos de resistências mecânicas significativos decorrentes das reações que ocorrem na zona de transição, onde os géis podem se tornar ricos em cálcio, agregando resistências no ponto que é considerado o mais frágil em argamassas e concretos convencionais. As quedas de resistência nas últimas idades demonstram a intensificação desta reação, onde a dissolução das fases reativas e geração de tensões pelos produtos formados acarretam neste comportamento.

As argamassas com agregado Pirita, o qual apresentou apenas ataque por sulfatos pela presença de pirita, demonstraram que os ciclos de ganhos e perdas de resistências mecânicas são decorrentes da colmatação de poros e fissuras pela formação de sais de sulfatos. Esta variação pode ser observada mais significativamente nos ensaios de resistência à tração por compressão diametral, visto que é neste ensaio que fica explicita a ocorrência do efeito de entrelaçamento de cristais de sulfatos visto o caráter frágil da fratura por tração dos compósitos de matriz cimentícia.

Desta forma, pelas análises procedidas, entende-se que a RAA irá ocorrer primeiramente nas zonas de transição entre pasta e agregado, alterando as resistências mecânicas, mesmo sem ser possível a sua observação em escalas maiores pelos ensaios de microscopia, podendo atribuir isto à capacidade de aumento de resistência de ligação na zona de transição. Já o ataque interno por sulfatos evidencia a sua influência quanto às resistências mecânicas, visto que o refinamento de poros e fissuras pôde ser observado pelos ensaios de microscopia, além da formação de sais de sulfatos identificados por DRX.

\section{Agradecimentos}

Ao laboratório multiusuários - CLABMU da UEPG. Ao Instituto LACTEC pela participação no Programa de P\&D ANEEL, projeto 6491-0301/2013, e à Universidade Federal do Paraná pela colaboração durante o desenvolvimento deste trabalho.

\section{Referências}

[1] WERITZ, F.; TAFFE, A.; SCHAURICH, D.; WILSCH, G. Detailed depth profiles of sulfate ingress into concrete measured with laser induced breakdown spectroscopy. Constructon and Building Materials. vol. 23, pp. 275 $-283,2009$.

[2] ÇULLU, M.; ARSLAN, M. The effects of chemical attacks on physical and mechanical properties of concrete produced under cold weather conditions. Construction and Building Materials. vol. 57, pp. 53-60, 2014.

[3] PEREIRA, Eduardo. Investigação e monitoramento do ataque por sulfatos de origem interna em concretos nas primeiras idades. Tese (Doutorado). 
PEREIRA, E. et al., AVALIAÇÃO DO EFEITO COMBINADO DA REAÇÃO ÁLCALI-AGREGADO (RAA) E ATAQUE INTERNO POR SULFATOS (ISA) SOBRE AS RESISTÊNCIAS MECÂNICAS E MICROESTRUTURA DE ARGAMASSSAS EM CURA IMERSA EM SOLUÇÃO DE HIDRÓXIDO DE SÓDIO. $3^{\circ}$ Simpósio Paranaense de Patologia das Construções (30 SPPC), artigo 3SPPC1008, pp. 84 - 95, 2018. DOI: $10.4322 / 2526-7248.008$

Programa de Pós-Graduação em Engenharia e Ciência de Materiais. Universidade Federal do Paraná. Curitiba, 2015.

[4] FURNAS. Equipe de Laboratório de Concreto. Concreto massa, estrutural, projetado e compactado com rolo - Ensaios e propriedades. São Paulo: Walton Pacelli de Andrade. PINI, 1997.

[5] MEHTA, P. K.; MONTEIRO, P. J. M. Concreto - estrutura, propriedades e materiais. São Paulo: Ed. Pini, 2008.

[6] SNYDER, Kenneth A.; LEW, Hai S. Alkali-Silica Reaction Degradation of Nuclear Power Plant Concrete Structures: A Scoping Study. NIST Interagency/Internal Report (NISTIR)-7937, 2013.

[7] FORADADA, J. S. Envejecimiento de presas por reacciones expansivas en hormigón. Minor thesis. Universitat Politècnica de Catalunya. Barcelona, 2005.

[8] ASSOCIAÇÃO BRASILEIRA DE NORMAS TÉCNICAS. NBR 7215 - Cimento Portland - Determinação da resistência à compressão. Rio de Janeiro, 1996.

[9] 2009. NBR 7211 - Agregados para concreto - Especificação. Rio de Janeiro,

[10] _ NBR NM 248 - Agregados - Determinação da composição granulométrica. Rio de Janeiro, 2003.

[11] _. NBR NM 52 - Agregado miúdo - Determinação da massa específica e massa específica aparente. Rio de Janeiro, 2009.

[12] .NBR NM 45 - Agregados - Determinação da massa unitária e do volume de vazios. Rio de Janeiro, 2006.

NBR NM 46 - Agregados - Determinação do material fino que passa através da peneira $75 \mu \mathrm{m}$, por lavagem. Rio de Janeiro, 2003.

NBR 13583 - Cimento Portland - Determinação da variação dimensional de barras de argamassa de cimento Portland expostas à solução de sulfato de sódio. Rio de Janeiro, 2014. NBR 5739 - Concreto - Ensaios de compressão de corpos-de-prova cilíndricos. Rio de Janeiro, 2007. NBR 7222 - Cimento Portland composto. Rio de Janeiro, 1997. tração por compressão diametral de corpos de prova cilíndricos. Rio de Janeiro, 2011.

[18] YURTDAS, Ismael et al. Influence of alkali silica reaction (ASR) on mechanical properties of mortar. Construction and Building Materials, v. 47, p. 165-174, 2013. 